\title{
Unusual 1,6-Diphenyl-1,3,5-hexatriene (DPH) Spectrophotometric Behavior in Water/Ethanol and Water/DMSO Mixtures
}

\author{
Augusto C. Gracetto, ${ }^{a}$ Vagner R. Batistela,${ }^{a}$ Wilker Caetano, ${ }^{a}$ Hueder P. M. de Oliveira,${ }^{b}$ \\ Willy Glen Santos, ${ }^{c}$ Carla C. S. Cavalheiro ${ }^{c}$ and Noboru Hioka ${ }^{*, a}$ \\ ${ }^{a}$ Departamento de Química, Universidade Estadual de Maringá, Av. Colombo 5.790, \\ 87020-900 Maringá-PR, Brazil \\ ${ }^{b}$ Universidade Camilo Castelo Branco, São José dos Campos, 12247-004 São Paulo-SP, Brazil \\ 'Instituto de Química, Universidade de São Paulo, CP 780, 13560-970 São Carlos-SP, Brazil
}

\begin{abstract}
O espectro de absorção de DPH, em concentração fixa, não varia com o teor de água em solvente orgânico. Tem-se a banda de monômeros igual àquela em etanol puro. A absorção não muda até o limite de 54 e $46 \%$ de água em etanol e DMSO, respectivamente, para [DPH] $=5,0 \times 10^{-6} \mathrm{~mol} \mathrm{~L}^{-1}$ a $30{ }^{\circ} \mathrm{C}$. Entretanto, em misturas com água muito abaixo desses conteúdos críticos, observou-se um decaimento intenso de fluorescência enquanto a absorção manteve-se constante. Propõese que moléculas de água atuam como supressores dos estados excitados e a constante de supressão de Stern-Volmer através de intensidade relativas, resultou em 7,4 × 10-2 (água/etanol) e $2,6 \times 10^{-2} \mathrm{~L} \mathrm{~mol}^{-1}$ (água/DMSO). Os tempos de vida do DPH na ausência e presença do supressor forneceram constantes de $7,1 \times 10^{-2} \mathrm{~L} \mathrm{~mol}^{-1}$ em água/etanol, indicando supressão dinâmica. Em investigações de ambientes com esta sonda, este processo deve ser considerado tendo em vista o risco de erros de interpretação.
\end{abstract}

The absorption spectra of DPH at fixed concentration do not change with water content in organic solvents. It exhibits monomer bands, such as those obtained in ethanol. The absorption did not change for solutions up to 54 and $46 \%$ of water in ethanol and DMSO, respectively, for $[\mathrm{DPH}]=5.0 \times 10^{-6} \mathrm{~mol} \mathrm{~L}^{-1}$ at $30^{\circ} \mathrm{C}$. However, at the same experimental conditions, a gradual sharp decay of the DPH fluorescence is observed. It is proposed that water molecules below these water concentration limits act as quenchers of the excited states of DPH. Stern-Volmer quenching constants by intensities measurements are $7.4 \times 10^{-2}$ (water/ethanol) and $2.6 \times 10^{-2} \mathrm{~L} \mathrm{~mol}^{-1}$ (water/DMSO). DPH lifetime measurements in the absence and presence of water resulted in $7.1 \times 10^{-2} \mathrm{~L} \mathrm{~mol}^{-1}$ in water/ethanol, which pointed out that the process is a dynamic quenching by water molecules. For experiments using DPH as probe, this process can affect data, leading to misunderstanding interpretation.

Keywords: diphenylhexatriene, DPH, DPH fluorescence, dynamic quenching, lifetime

\section{Introduction}

trans-1,6-Diphenyl-1,3,5-hexatriene (DPH), which is used as a fluorescence probe, has a rod-like structure that absorbs and emits light with a high quantum efficiency, although it is not a large conjugative $\pi$-electron system. ${ }^{1,2}$ The spectrophotometric properties of DPH are very sensitive to the experimental conditions, which allows using this compound and its derivatives as environmental probes in colloidal systems to determine the critical

*e-mail: nhioka@uem.br micellar concentration of surfactants ${ }^{3}$ and in biological cell membranes. ${ }^{4,5}$ The measurement of the fluorescence anisotropy of DPH is extensively used for membranes, particularly in studies of microviscosities, ${ }^{6}$ due to the non-polar characteristic, the low water solubility, and the suitable geometric design, which maintains the molecule aligned parallel to the phospholipids chains of the membranes. ${ }^{7}$ Although the DPH molecule remains inserted in the membrane layer, it stays in contact with water molecules. ${ }^{2,5}$

The majority of DPH spectrophotometric studies on electronic transitions are performed in organic solvents. ${ }^{1,2,8-14}$ 


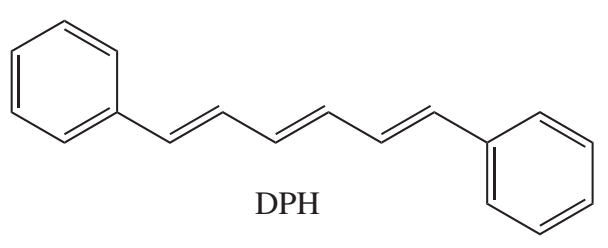

For DPH, the ground state $\left(\mathrm{S}_{0}\right)$ and the first excited state $\left(\mathrm{S}_{1}\right)$ have $\mathrm{A}_{\mathrm{g}}$ symmetry, while the second excited state $\left(\mathrm{S}_{2}\right)$ has $\mathrm{B}_{\mathrm{u}}$ symmetry. Therefore, the $\mathrm{S}_{0}-\mathrm{S}_{1}$ transition is not allowed by the symmetry rule, while the $\mathrm{S}_{\mathrm{o}}-\mathrm{S}_{2}$ transition is. ${ }^{10}$ Therefore, the DPH absorption band corresponds to the ${ }^{1} \mathrm{~A}_{\mathrm{g}}{ }^{-} \mathrm{B}_{\mathrm{u}}{ }^{*}\left(\mathrm{~S}_{\mathrm{o}}-\mathrm{S}_{2}\right)$ transition. In contrast, the very long fluorescence lifetime of DPH indicates that the emission does not correspond to a reverse ${ }^{1} \mathrm{~B}_{\mathrm{u}}{ }^{*}-{ }^{1} \mathrm{~A}_{\mathrm{g}}\left(\mathrm{S}_{2}-\mathrm{S}_{\mathrm{o}}\right)$ transition. As known, the ${ }^{1} \mathrm{~A}_{\mathrm{g}}{ }^{*}$ state $\left(\mathrm{S}_{1}\right)$ is more stable than the ${ }^{1} \mathrm{~B}_{\mathrm{u}}{ }^{*}$ state $\left(\mathrm{S}_{2}\right)$ in long diphenylpolyenes, such as DPH. Birks ${ }^{11,12}$ first suggested that the low $\mathrm{S}_{1}-\mathrm{S}_{2}$ energy difference, about $1000 \mathrm{~cm}^{-1}$ in hexane, allows coupling (Herzberg-Teller vibronic coupling) of both states, as shown by the energy diagram in Scheme 1. This coupling changes the "purity" state of ${ }^{1} \mathrm{~A}_{\mathrm{g}}^{*}$ by orbital symmetry modifications, thus diminishing the forbiddance of DPH $\mathrm{S}_{1}-\mathrm{S}_{\mathrm{o}}$ fluorescence emission after a quick non-radiative internal $S_{2}-S_{1}$ conversion. ${ }^{18}$ In fact, either fluorescence or rotation (cis-trans isomerization) occurs from ${ }^{1} \mathrm{~A}_{\mathrm{g}}^{*}\left(\mathrm{~S}_{1}\right.$ state). As the coupling diminishes, the fluorescence yield, $\Phi_{\mathrm{F}}$, decreases, while the cis-trans rotation increases. ${ }^{14}$

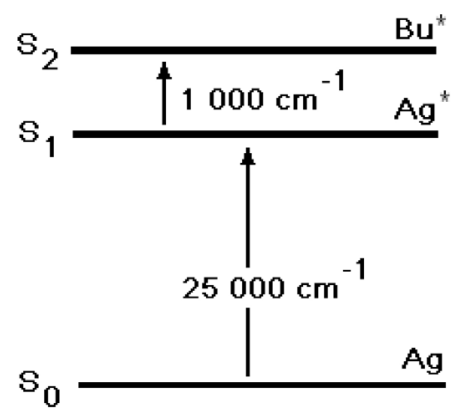

Scheme 1. Jablonski energetic diagram of DPH in hexane as reported in reference 14 .

Several spectrophotometric and photochemical properties of DPH depend on environmental factors such as the temperature, solvent nature, etc. They influence the energy diagram, particularly the energy gap of $\mathrm{S}_{1}-\mathrm{S}_{2}$ states and their coupling, and accordingly, so are the characteristics of the involved orbital. Orbital $\mathrm{A}_{\mathrm{g}}$ is assigned to a highly symmetric state, a "covalent" character, while the $\mathrm{B}_{\mathrm{u}}$ state presents more "ionic" characteristics. ${ }^{10}$ Therefore, the energy of the ${ }^{1} \mathrm{~A}_{\mathrm{g}}{ }^{-1} \mathrm{~B}_{\mathrm{u}}{ }^{*}\left(\mathrm{~S}_{\mathrm{o}}-\mathrm{S}_{2}\right.$ absorption) transition is affected by the solvent polarity and polarizability. A highly polar and polarizable solvent stabilizes the ${ }^{1} \mathrm{~B}_{\mathrm{u}}{ }^{*}$ state $\left(\mathrm{S}_{2}\right)$ better than the ${ }^{1} \mathrm{~A}_{\mathrm{g}}$ state $\left(\mathrm{S}_{\mathrm{o}}\right)$, which is less sensitive, leading to red-shifted absorption peaks. Dupuy and Montagu ${ }^{2}$ showed that the main absorptivity parameter of DPH is the solvent polarizability $\left(\alpha_{\mathrm{S}}\right)$ rather than the polarity, which is related to the refractive index. The higher the solvent refractive index, the greater the red-shifted absorption band..$^{1,2}$ However, the solvent nature does not affect the fluorescence wavelength, since the $\left(\mathrm{S}_{1}-\mathrm{S}_{\mathrm{o}}\right)$ process involves two $A_{g}$ orbitals, which suffer the same type of stabilization by the solvent and are less sensitive to polarizability. Additionally, a solvent with high polarizability stabilizes the $S_{2}$ orbital and favors the $S_{2}-S_{1}$ coupling, leading to a high fluorescence yield. ${ }^{9}{ }^{15}$ The slightly decrease in the polarizability of organic solvents with the increase in the temperature destabilizes the ${ }^{1} \mathrm{~B}_{\mathrm{u}}{ }^{*}$ state. The resulting decrease of the $S_{1}-S_{2}$ coupling promotes a decrease of $\Phi_{\mathrm{F}}{ }^{10,15,16}$ This effect is more evident in polar solvents, such as ethanol and acetonitrile, than in non-polar solvents. ${ }^{1}$ The present work investigated an unusual fluorescence behavior of DPH associated with the presence of water in organic solvents (ethanol and DMSO) attributed to DPH excited states quenching by water molecules.

\section{Experimental}

Anhydrous ethanol (Merck) and DMSO (Malinckrodt) were used as supplied. Sodium dodecyl sulfate (SDS) was purchased from Aldrich. Deionized and distilled water was used throughout. The DPH (all-trans, Aldrich) stock solutions were prepared in DMSO and kept frozen in the dark. Before use, the melted solutions were standardized by UV-Vis spectrophotometry in methanol (Merck) using a molar absorptivity of $\varepsilon_{350 \mathrm{~nm}}=88000 \mathrm{~L} \mathrm{~mol}^{-1} \mathrm{~cm}^{-1} \cdot{ }^{17}$ Approximately $100 \mathrm{~mL}$ of the solvent solution was prepared by mixing accurately measured volumes of water and organic solvents using a calibrated pipette. An aliquot of DPH stock solution was added to $2 \mathrm{~mL}$ of solvent mixture in a quartz cuvette using a micro syringe and agitated vigorously. The final samples contained no more than $0.07 \%(\mathrm{v} / \mathrm{v})$ of DMSO and its presence did not influence the experimental results. All experiments were carried out at $30{ }^{\circ} \mathrm{C}$. The absorption and fluorescence spectra were obtained in Varian Cary-50 and PerkinElmer LS-5 spectrometers, respectively. For fluorescence experiments, the excitation was fixed at $353 \mathrm{~nm}$ and the emission was monitored at $430 \mathrm{~nm}$. For Resonance Light Scattering spectra the spectrofluorometer were operated in synchronous mode $(\Delta \lambda=0)$. The lifetime measurements were conducted in equipment from Optical Building Blocks Corporation (OBBC) with excitation source at $370 \mathrm{~nm}$ (LED) and emission at $435 \mathrm{~nm}$, and the software 
EasyLife V. The fluorometer light exposure time was controlled to avoid DPH photodegradation. ${ }^{1}$ The amount of water is given as $\mathrm{v} / \mathrm{v}$ percentage in organic solvent.

\section{Results and Discussion}

The electronic absorption spectrum of DPH in anhydrous organic solvents, such as ethanol, methanol, and DMSO, exhibits a long wavelength band (300-400 nm) composed of three characteristic vibrational peaks and shoulders that correspond to DPH in monomeric form. The absorption and fluorescence spectra of monomeric DPH are illustrated in Figure 1. The lack of a mirror image between these spectra is due to the electronic states involved once the absorption corresponds to $\mathrm{S}_{\mathrm{o}}-\mathrm{S}_{2}{ }^{*}$ transition and the emission corresponds to $\mathrm{S}_{1}{ }^{*}-\mathrm{S}_{\mathrm{o}}$ transition. ${ }^{12,13}$

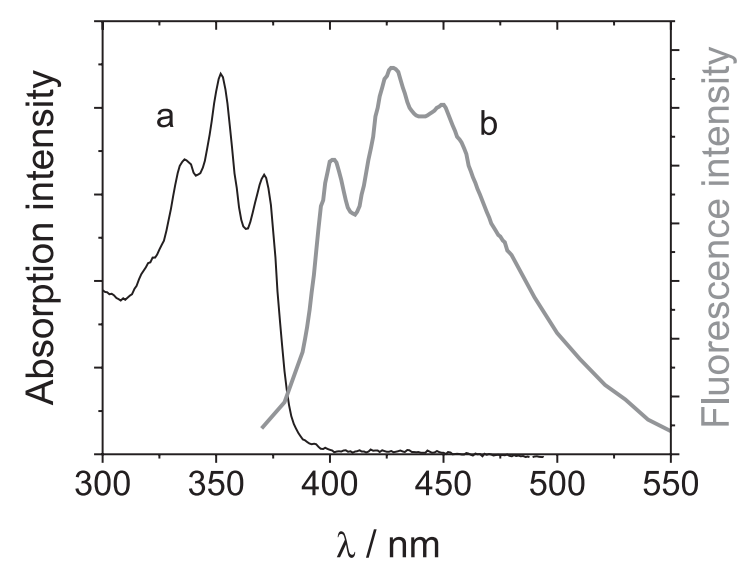

Figure 1. Absorption (a) and fluorescence (b) spectra of DPH in ethanol.

In the presence of large amounts of water in ethanol and in DMSO, the absorption spectra of DPH changed as illustrated in Figure 2 (water/ethanol system as an example). However, these changes for $[\mathrm{DPH}]=5.0 \times 10^{-6} \mathrm{~mol} \mathrm{~L}^{-1}$ at

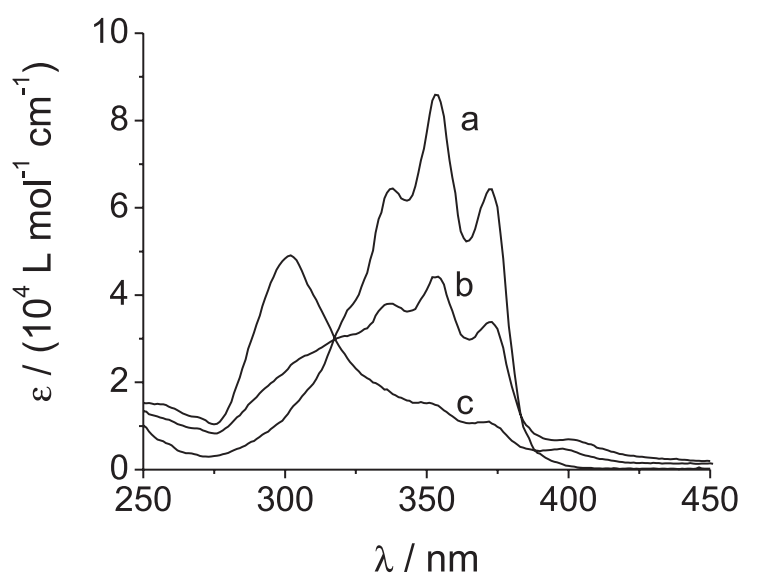

Figure 2. DPH absorption spectra in water/ethanol mixtures (water \%, v/v): (a) $0-54 \%$; (b) $60 \%$; and (c) $70 \%$. [DPH] $=5.0 \times 10^{-6} \mathrm{~mol} \mathrm{~L}^{-1}$. $\mathrm{T}=30^{\circ} \mathrm{C}$

$30{ }^{\circ} \mathrm{C}$ are observed only above $54 \%$ water in ethanol and $46 \%$ water in DMSO.

These absorption spectral changes, expressed by a strong decrease in the intensity of the peak around $353 \mathrm{~nm}$ (the most intense monomer absorption peak) and a new absorption band at $300 \mathrm{~nm}$, may be attributed to a DPH self-aggregation process that leads to dimers, trimers, and other aggregates. These results will not be discussed in the present report ${ }^{18}$ as its focus is presently on the experimental conditions below this critical amount of water and the resulting effects observed on the spectrophotometric properties of DPH. Therefore, all subsequent results are related to these water ranges, below $54 \%$ water in ethanol and below $46 \%$ in DMSO for $[\mathrm{DPH}]=5.0 \times 10^{-6} \mathrm{~mol} \mathrm{~L}^{-1}$ at $30{ }^{\circ} \mathrm{C}$. In these ranges, while the absorption spectra did not vary, remaining almost the same as in anhydrous organic solvents, the fluorescence decays even for low water contents as illustrated in Figure 3. Indeed the absorbance at $353 \mathrm{~nm}$ presented a linear correlation
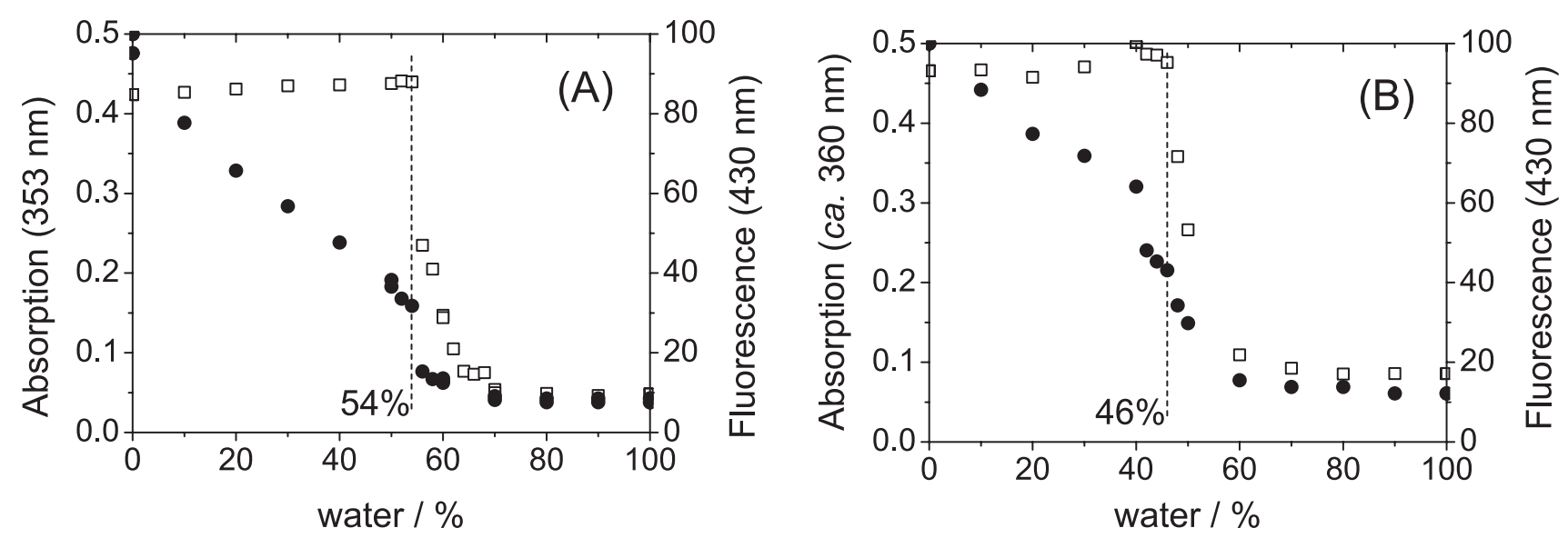

Figure 3. Absorption $(\square)$ and fluorescence $(\bullet)$ intensities as a function of water percentage for: (A) EtOH and (B) DMSO mixtures. $[\mathrm{DPH}]=5.0 \times 10^{-6} \mathrm{~mol} \mathrm{~L}^{-1}$ and $30^{\circ} \mathrm{C}$. The dashed lines indicate the critical water percentage of self-aggregation process. 
with DPH concentration (Beer's plot) for [DPH] up to $5.0 \times 10^{-6} \mathrm{~mol} \mathrm{~L}^{-1}$ in water/ethanol solution (experiment series at water ranging from 0 to $40 \%$ ), not shown.

The absence of new absorption bands or peak shifts in the absorption and fluorescence spectra of DPH makes the isomerization hypothesis improbable, since cis-polyenes usually exhibit blue-shifted absorption bands when compared to trans-polyenes. ${ }^{19}$ This effect of water on the DPH fluorescence was previously reported by Dupuy and Montagu. ${ }^{2}$ In that work the fluorescence intensity decayed 16 and $29 \%$ in ethanol, and 3 and $13 \%$ in DMSO for 3 and $10 \%$ water, respectively. They assigned this phenomenon to DPH and water interactions without further discussion. ${ }^{5}$ While water does not shift the wavelength of the emission bands, its low polarizability, $\alpha_{\text {S, water }}=0.206$, compared to 0.222 of ethanol and 0.284 of DMSO at $30^{\circ} \mathrm{C}$, destabilizes the $\mathrm{S}_{2}$ orbital and reduces the $\mathrm{S}_{2}-\mathrm{S}_{1}$ coupling, which are reflected as a weak fluorescence emission (low $\Phi_{\mathrm{F}}$ ). ${ }^{9,15}$ However, the large decrease in the fluorescence intensity for such low water percentage in the solvent cannot be attributed to a simple solvent polarizability effect, as demonstrated by the fluorescence intensity decay of $27 \%$ for the addition of $10 \%$ water in methanol. ${ }^{2}$ The $\alpha_{\mathrm{S}}$ of methanol is even smaller than that of water $\left(\alpha_{\mathrm{S} \text {, methanol }}=0.203\right)$. As the same time the observed fluorescence decrease can not be attributed to dielectric constant effects. Therefore, a specific mechanism of quenching process should exist, which promotes DPH fluorescence decreases. The fluorescence data was applied to the Stern-Volmer equation (1), considering water molecules acting as the quenchers:

$$
\frac{\mathrm{F}_{\mathrm{o}}}{\mathrm{F}}=1+\mathrm{K}_{\mathrm{SV}}\left[\mathrm{H}_{2} \mathrm{O}\right]
$$

where $\mathrm{F}_{\mathrm{o}}$ is DPH fluorescence intensity in organic solvent, $\mathrm{F}$ is observed fluorescence intensity, $\mathrm{K}_{\mathrm{SV}}$ is Stern-Volmer quenching constant and $\left[\mathrm{H}_{2} \mathrm{O}\right]$ is water molar concentration. The plots of $\mathrm{F}_{\mathrm{o}} / \mathrm{F}$ against $\left[\mathrm{H}_{2} \mathrm{O}\right]$ for three fixed $\mathrm{DPH}$ concentrations are illustrated in Figure 4.

All plots in Figure 4 show linear dependence upon the quencher concentration. Table 1 shows the $\mathrm{K}_{\mathrm{SV}}$ values and the correlation coefficients (cc) of the fluorescence data. Figure 4 and the results in Table 1 show the excellent curve fitting and that the Stern-Volmer constants are independent of the DPH concentration. The average $\mathrm{K}_{\mathrm{SV}}$ value for the DPH in water/ethanol mixtures resulted in $7.4 \times 10^{-2} \mathrm{~L} \mathrm{~mol}^{-1}$ while in water/DMSO $2.6 \times 10^{-2} \mathrm{~L} \mathrm{~mol}^{-1}$ with cc $=0.9977$. Therefore, it is demonstrated that the water molecules are acting as quenchers.

In the present work, two basic mechanisms: the dynamic (or collisional) quenching and the static quenching can be

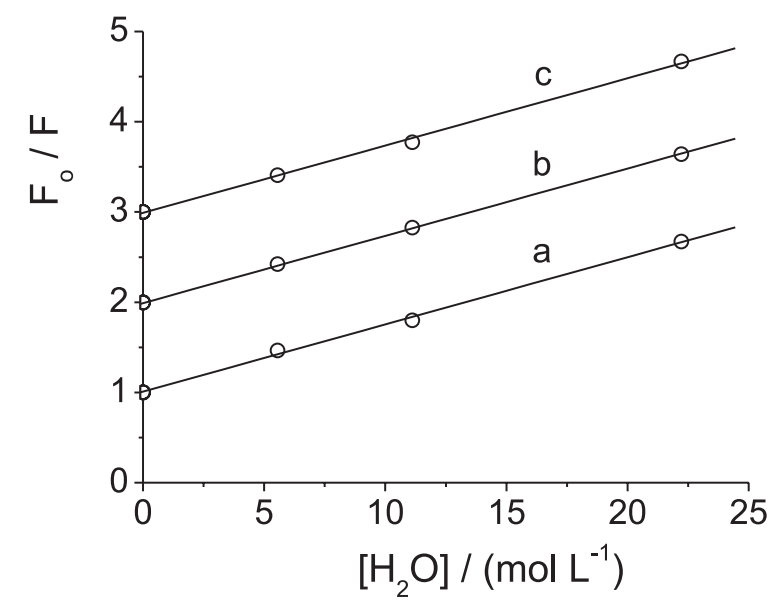

Figure 4. Stern-Volmer plot. Fixed DPH concentration at: (a) $0.18 \times 10^{-6} \mathrm{~mol} \mathrm{~L}^{-1}$; (b) $0.47 \times 10^{-6} \mathrm{~mol} \mathrm{~L}^{-1}$; and (c) $0.67 \times 10^{-6} \mathrm{~mol} \mathrm{~L}^{-1}$. Water/ethanol mixtures at $30{ }^{\circ} \mathrm{C}$. The values of $\mathrm{F}_{0} / \mathrm{F}$ (y-axis) for (b) and (c) curves are increased by, respectively, +1 unit and +2 units, to permit the visualization of the adjustment.

Table 1. Values of $\mathrm{K}_{\mathrm{SV}}$ and correlation coefficients (cc) obtained by the fitting of experimental data for DPH fluorescence measurements at $30^{\circ} \mathrm{C}$ in water/ethanol mixtures

\begin{tabular}{ccc}
\hline$[\mathrm{DPH}]\left(10^{-6} \mathrm{~mol} \mathrm{~L}^{-1}\right)$ & $\mathrm{K}_{\mathrm{SV}}\left(\mathrm{L} \mathrm{mol}^{-1}\right)$ & $\mathrm{cc}$ \\
\hline 0.18 & $0.074 \pm 0.002$ & 0.9991 \\
0.47 & $0.074 \pm 0.001$ & 0.9999 \\
0.67 & $0.073 \pm 0.002$ & 0.9993 \\
\hline
\end{tabular}

responsible for DPH deactivation. A similar $\Phi_{\mathrm{F}}$ decay in aqueous solutions of fluoresceins $\mathrm{s}^{20,21}$ and cumarins ${ }^{22}$ was attributed to specific water molecule interactions caused by hydrogen bonding, as discussed by Arbeloa. ${ }^{20}$ Although hydrogen bonding or even polar-polar interactions are not recognizable for DPH, some authors have reported experimental and theoretical ground state benzene-water weak structures in which the aromatic rings would act as hydrogen bond acceptors. ${ }^{23}$ For DPH, as reported, ${ }^{10}$ the $\mathrm{S}_{2}{ }^{*}$ electronic state $\left({ }^{1} \mathrm{~B}_{u}^{*}\right)$ of DPH is assigned as more "ionic" symmetry and there is a $S_{2}{ }^{*}-S_{1}{ }^{*}$ coupling that changes the "purity" of both states, ${ }^{12}$ which may turn the $S_{1}{ }^{*}$ state more "ionic", so that more sensible to interactions.

The fluorescence measurements at 30 and at $50{ }^{\circ} \mathrm{C}$, represented as $\mathrm{F}_{30}$ and $\mathrm{F}_{50}$, respectively, showed a decrease in the intensity at higher temperatures for the water percentage range considered $\left(\mathrm{F}_{50} / \mathrm{F}_{30}\right.$ ratio $\left.<1\right)$. This effect was first explained by Alford and Palmer, ${ }^{16}$ who attributed it to a small decrease in polarizability with the rise in temperature, which destabilized the $S_{2}$ orbital and resulted in the $S_{2}-S_{1}$ decoupling (decrease in $\Phi_{\mathrm{F}}$ ). Additionally the temperature elevation favors internal conversion instead fluorescence emission. However, another explanation for the present case is the viscosity diminution as the temperature 
increases, resulting in faster diffusion and hence larger amounts of collisions (higher energy suppression), which suggests dynamic quenching. The value of the $\mathrm{F}_{50} / \mathrm{F}_{30}$ ratio was independent of the water content. Additionally, the fluorescence intensity decayed even with the addition of SDS to an aqueous ethanolic solution of DPH (not shown). These results eliminate the possibility of DPH self-aggregation for water contents below the previously mentioned critical water concentration, since the increase in temperature and the addition of surfactant cause monomer formation, which should result in higher fluorescence..$^{24}$ In addition Resonance Light Scattering (RLS) experiments using the spectrofluorometer in synchronous mode did not show RLS signals that pointed out absence of aggregates in these solutions.

To confirm that the DPH fluorescence diminution by water molecules follows the mechanism of dynamic quenching, time-resolved experiments were performed at several water/ethanol conditions (Figure 5). From the data exposed in Figure 5, the fluorescence lifetimes of DPH in the absence $\left(\tau_{0}\right)$ and presence $(\tau)$ of quenchers were calculated. The obtained lifetime of DPH in pure ethanol $\left(\tau_{\mathrm{o}}=5.0 \mathrm{~ns}\right)$ is in accordance to the value found in the literature ${ }^{1}(5.0 \mathrm{~ns}$ at $32{ }^{\circ} \mathrm{C}$ in the absence of oxygen). Figure 6 presents the plot of $\tau_{0} / \tau$ against water molar concentration.

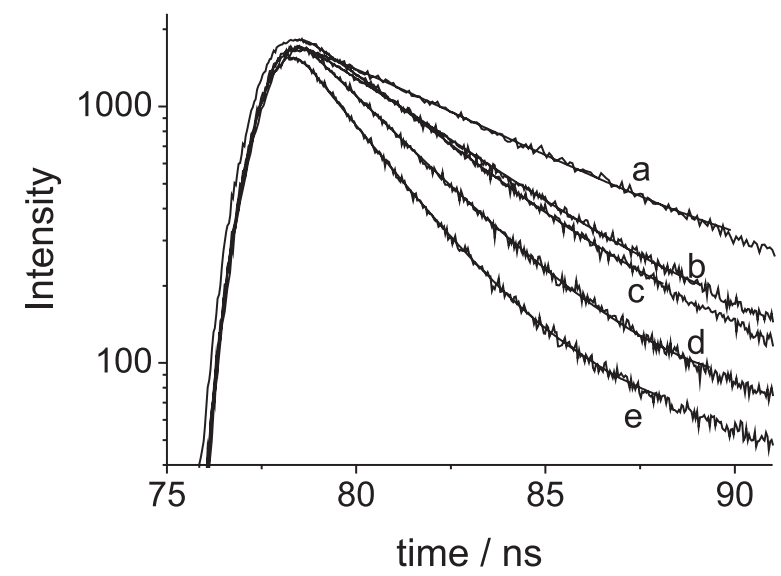

Figure 5. Lifetime determinations for DPH in different water/ethanol mixtures: (a) pure ethanol; (b) $10 \%$; (c) $20 \%$; (d) $30 \%$; and (e) $40 \%$ of water $(\mathrm{v} / \mathrm{v})$. $[\mathrm{DPH}]=0.5 \times 10^{-6} \mathrm{~mol} \mathrm{~L}^{-1}$. Excitation at $370 \mathrm{~nm}$ and emission at $435 \mathrm{~nm}$.

As can be seen, the plot in Figure 6 follows a linear relationship whose slope is $7.1 \times 10^{-2} \mathrm{~L} \mathrm{~mol}^{-1}$. This value is the same as the $\mathrm{K}_{\mathrm{SV}}$ obtained from fluorescence steadstate results $\left(7.4 \times 10^{-2} \mathrm{~L} \mathrm{~mol}^{-1}\right)$. The equivalence of the ratios, $\mathrm{F}_{\mathrm{o}} / \mathrm{F}$ (Figure 4 ) and $\tau_{\mathrm{o}} / \tau$ (Figure 6 ), demonstrates that the investigated fluorescence decay is due to dynamic quenching of the DPH excited states by water molecules. Indeed, the calculated bimolecular quenching constant

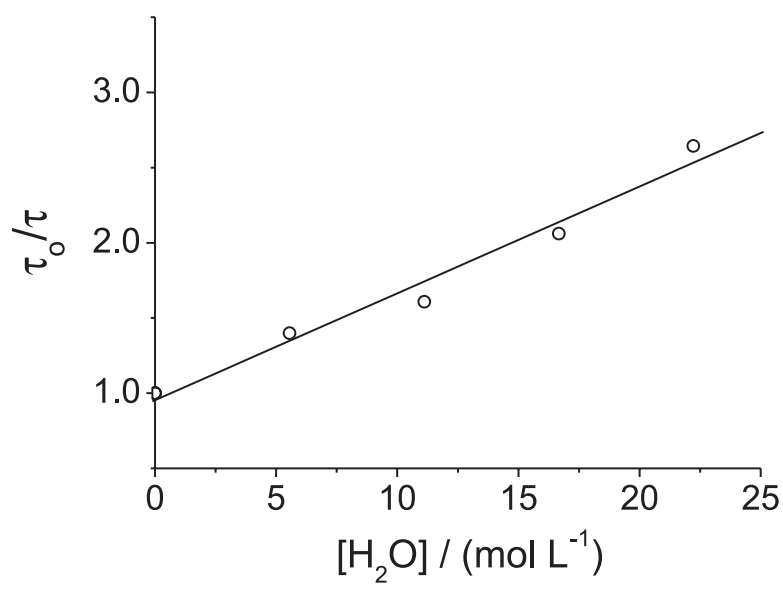

Figure 6. Lifetime relationship $(\tau / \tau)$ for DPH at several water molar concentration for $[\mathrm{DPH}]=0.5 \times 10^{-6} \mathrm{~mol} \mathrm{~L}-1 . \mathrm{T} c a .22{ }^{\circ} \mathrm{C}$.

$\mathrm{k}_{\mathrm{q}} c a .1 .5 \times 10^{7} \mathrm{~L} \mathrm{~mol}^{-1} \mathrm{~s}^{-1}$ (calculated from $\tau_{\mathrm{o}}$ and $\mathrm{K}_{\mathrm{Sv}}$ ) is smaller than the typical diffusion-controlled value, which shows low quenching efficiency.

\section{Conclusion}

Once DPH is used as probe for colloid and membrane investigations, the large fluorescence decay of DPH in presence of water must be taken into account. Despite being hydrophobic, the DPH probe can be exposed to water molecules in some microenvironments. This quenching process can affect experimental data, leading to misunderstanding interpretation. The deactivation mechanism of excited states of DPH is due to the dynamic quenching by water molecules.

\section{Acknowledgments}

This work was supported by the Brazilian agencies: Fundação Araucária-Seti/Paraná, FAPESP, CNPq and CAPES NanoBiotec. The authors want to thank Laerte J. da Silva for the English language revision.

\section{References}

1. Cehelnik, E. D.; Cundall, R. B.; Lockwood, J. R.; Palmer, T. F.; J. Phys. Chem. 1975, 79, 1369.

2. Dupuy, B.; Montagu, M.; Analyst 1997, 122, 783.

3. Alexandridis, P.; Holzwarth, J. F.; Hatton, T. A.; Macromolecules 1994, 27, 2414; Hioka, N.; Chowdhary, R. K.; Chansarkar, N.; Delmarre, D.; Stenberg, E.; Dolphin, D.; Can. J. Chem. 2002, 80, 1321; Gaisford, S.; Beezer, A. E.; Mitchell, J. C.; Bell, P. C.; Fakorede, F.; Finnie, J. K.; Williams, S. J.; Int. J. Pharm. 1998, 174, 39.

4. Shinitzky, M.; Barenholz, Y.; J. Biol. Chem. 1974, 249, 2652. 
5. Trotter, P. J.; Storch, J.; Biochim. Biophys. Acta, Biomembr. 1989, 982, 131.

6. Soto, M. A.; Sotomayor, C. P.; Lissi, E. A.; J. Photochem. Photobiol., A 2002, 152, 79; Lakowicz, J. R.; Principles of Fluorescence Spectroscopy, $2^{\text {nd }}$ ed.; Plenum Press: New York, 1994.

7. Shinitzky, M.; Barenholz, Y.; Biochim. Biophys. Acta, Biomembr. 1978, 515, 367.

8. Turek, A. M.; Krishnamoorthy, G.; Sears, D. F.; Garcia, I.; Dmitrenko, O.; Saltiel, J.; J. Phys. Chem. A 2005, 109, 293; Hilinski, E. F.; McGowan, W. M.; Sears, D. F.; Saltiel, J.; J. Phys. Chem. 1996, 100, 3308.

9. Itoh, T.; Kohler, B. E.; J. Phys. Chem. 1987, 91, 1760.

10. Allen, M. T.; Whitten, D. G.; Chem. Rev. 1989, 89, 1691.

11. Birks, J. B.; Birch, D. J. S.; Chem. Phys. Lett. 1975, 31, 608; Birks, J. B.; Chem. Phys. Lett. 1978, 54, 430.

12. Birks, J. B.; Tripathi, G. N. R.; Lumb, M. D.; Chem. Phys. 1978, 33,185 .

13. Saltiel, J.; Wang, S.; J. Am. Chem. Soc. 1995, 117, 10761.

14. Saltiel, J.; Ko, D. H.; Fleming, S. A.; J. Am. Chem. Soc. 1994, 116, 4099.

15. Allen, M. T.; Miola, L.; Whitten, D. G.; J. Phys. Chem. 1987, 91, 6099.

16. Alford, P. C.; Palmer, T. F.; Chem. Phys. Lett. 1982, 86, 248.

17. Haugland, R. P.; Handbook of Fluorescent Probes and Research Chemicals, $6^{\text {th }}$ ed.; Molecular Probes Inc.: New York, 1996.
18. Gracetto, A. C.; Batistela, V. R.; de Oliveira, H. P. M.; Hioka, $\mathrm{N}$.; unpublished work.

19. Lunde, K.; Zechmeister, L.; J. Am. Chem. Soc. 1954, 76, 2308.

20. Arbeloa, F. L.; Arbeloa, T. L.; Bartolome, P. H.; Estevez, M. J. T.; Arbeloa, I. L.; Proc. Indian Acad. Sci. (Chem. Sci.) 1992, $104,165$.

21. Arbeloa, F. L.; Arbeloa, T. L.; Estevez, M. J. T.; Arbeloa, I. L.; J. Phys. Chem. 1991, 95, 2203; Arbeloa, F. L.; Arbeloa, T. L.; Arbeloa, I. L.; Costela, A.; Garcia-Moreno, I.; Figueira, J. M.; Amat-Guerri, F.; Sastre, R.; J. Lumin. 1997, 75, 309.

22. Arbeloa, F. L.; Arbeloa, T. L.; Arbeloa, I. L.; J. Lumin. 1996, $68,149$.

23. Suzuki, S.; Green, P. G.; Bumgarner, R. E.; Dasgupta, S.; Goddard, W. A.; Blake, G. A.; Science 1992, 257, 942; Li, S.; Cooper, V. R.; Thonhauser, T.; Puzder, A.; Langreth, D. C.; J. Phys. Chem. A 2008, 112, 9031.

24. Simplicio, F. I.; Maionchi, F.; Santin Filho, O.; Hioka, N.; J. Phys. Org. Chem. 2004, 17, 325; Simplicio, F. I.; Soares, R. R. S.; Maionchi, F.; Santin Filho, O.; Hioka, N.; J. Phys. Chem. A 2004, 108, 9384.

Received: January 18, 2010

Web Release Date: April 12, 2010

FAPESP has sponsored the publication of this article. 